\title{
Total knee arthroplasty using modified measured resection: a five-year retrospective review of midterm outcomes
}

\author{
Tran T. Dung ${ }^{1}$, Vo S. Q. Nang², Dinh N. Son ${ }^{3}$, Hoang G. Dư , Nguyen H. Long 5 , Le M. Son ${ }^{5}$, \\ Duong D. Toan ${ }^{3}$, Do V. Minh'2, Nguyen H. Phuong' ${ }^{1}$, Ma N. Thanh ${ }^{2}$
}

\author{
${ }^{1}$ Hanoi Medical University; Saint Paul University Hospital; Hanoi Medical University \\ Hospital, Vietnam \\ ${ }^{2}$ Hanoi Medical University; Hanoi Medical University Hospital, Vietnam \\ ${ }^{3}$ Hanoi Medical University; Vietduc University Hospital, Vietnam \\ ${ }^{4}$ Hanoi Medical University; Bachmai University Hospital, Vietnam \\ ${ }^{5}$ Vietduc University Hospital, Vietnam
}

Submitted: 19 March 2019; Accepted: 22 May 2019;

Online publication: 9 September 2019

Arch Med Sci 2021; 17 (2): 397-405

DOI: https://doi.org/10.5114/aoms.2019.87689

Copyright $\odot 2019$ Termedia \& Banach

\begin{abstract}
Introduction: Deforming arthrosis, or osteoarthritis, is the most common rheumatic disease that involves the musculoskeletal system. The purpose of this research is to perform a retrospective review of the quality of life of patients with knee arthrosis, who underwent total knee arthroplasty (TKA) no less than 5 years ago, to evaluate, based on the Knee Society Scoring System, the efficacy of a modified measured resection technique, and to investigate factors that affect the outcomes.

Material and methods: The research sample consisted of 44 patients who had severe osteoarthrosis, Kellgren-Lawrence grade III and grade IV.

Results: The post-operative complications occurred in seven knee joints. Among them there were 2 cases of infection, 2 cases of periprosthesis fracture, and 2 cases of aseptic instability, each pair accounting for $4.3 \%$, and 1 case of femoropatellar pain (2.3\%). The remaining 38 knee joints (84.8\%) were free of complications.

Conclusions: Knee arthrosis is a serious health problem, given the significant rate of disability among patients and the significant reduction in the quality of life. Patients often seek medical help at the later stages of the disease, when pain is strong and knee function is significantly reduced. The approach to rehabilitation procedures and, in some cases, to lifestyle improvement should be more responsible.
\end{abstract}

Key words: total knee arthroplasty, modified measured resection technique, Knee Society Scoring System, retrospective review.

\section{Introduction}

Deforming arthrosis, or osteoarthritis, is the most common rheumatic disease that involves the musculoskeletal system [1, 2]. It is considered a major medical and social problem. This disease is a condition that represents a pathological imbalance of degradative and reparative processes involving the cartilage and the subchondral bone, with inflammation of the synovium tissue [3]. According to epidemiological stud-

\author{
Corresponding author: \\ Tran T. Dung \\ Hanoi Medical University \\ Saint Paul University Hospital \\ Hanoi Medical University \\ Hospital \\ Vietnam \\ E-mail: dung.tran@inbox.ru; \\ dungbacsy@hmu.edu.vn
}


ies, this pathology affects from $8 \%$ to $20 \%$ of the adult population, of which $33 \%$ of osteoarthritis cases are attributed to knee arthrosis. As of 2010, $3.6 \%$ of the world's population had knee arthrosis $[1,2,4]$. In the Zoetermeer Community Survey, the $\mathrm{X}$-ray data on the prevalence of knee arthrosis indicated 14,100 men and 22,800 women, over 45 years of age, in every 100,000 [5]. Clinical signs of knee arthrosis arise much less frequently than do radiographic signs. The prevalence rate of knee osteoarthritis increases significantly with age. According to various data, symptomatic gonarthrosis occurs in $5 \%$ of the population under the age of 30 years, in $8 \%$ of the population in the $30-40$-year age group, in $16.7 \%$ of the population from the $40-50$-year age group, in $20 \%$ of the population from the 50-60-year age group, and in more than $30 \%$ of the population over 60 years of age. What is more, this disease develops 1.2-1.4 times more often in women than in men $[6,7]$.

The risk factors for deforming arthrosis of the knee joint are: older age, being female, high physical activity, and obesity. High bone mineral density, history of injuries, hormone replacement therapy, low intake of antioxidants, vitamin C and D, quadriceps muscle weakness, intense athletic activity, and smoking are also significant $[8,9]$.

Thus, mechanical, biochemical, and genetic factors are involved in osteoarthrosis development and progression, as well as in the inflammation processes that may take place in the subchondral bone, in hyaline cartilage, in synovium tissue, and in the periarticular soft tissues [10]. As this disease progresses, it may cause disability over several years or dozens of years. Patients often seek medical help at the later stages of the disease, when pain is strong and knee function is significantly reduced. At this stage, conservative therapy is no longer effective, and TKA remains the only way to improve the quality of life $(\mathrm{Q} o \mathrm{~L})$ of patients. Patients with deforming arthrosis make up about one third of all people with permanent disability caused by problems with the knee joints. Thus, this disease can be considered socially significant, given the increase in the rate of disability associated with it and the decline in the quality of life of affected people $[11,12]$.

The clinical presentation of osteoarthritis includes arthralgia, pain, reduced range of movement, crepitus, a periodic accumulation of effusion in the joint cavity, an inflammatory process of varying severity without systemic manifestations. The pathological process affects not only the articular cartilage, but also extends to the entire joint, including the subchondral bone, ligaments, capsule, synovial membrane, and periarticular muscles. Ultimately there is degeneration of the articular cartilage with its disintegration, the formation of cracks, ulceration, and its complete loss, a sharp thickening and densification of the cortical layer of the subchondral bone, osteophytosis, and formation of subchondral cysts [13-15].

The treatment of gonarthrosis remains challenging. Patients usually visit the doctor at the later stages of disease [16]. At present, total knee arthroplasty is the most effective surgical method for treating late diagnosed degenerative-dystrophic diseases of the knee joint when the conservative therapy did not work (Figure 1). By replacing the knee joint with an artificial joint, one may achieve pain relief in the shortest time possible, deal away the associated deformation, and restore the joint function [17]. Total knee arthroplasty is generally recognised, from both clinical $[18,19]$ and economic standpoints $[20,21]$, as a successful surgical procedure.

The classical techniques that are currently employed in total knee arthroplasty are measured resection and gap balancing, which are used in various modifications. Artificial parts that are used are from various manufacturers. The endoprostheses are constantly being improved to increase
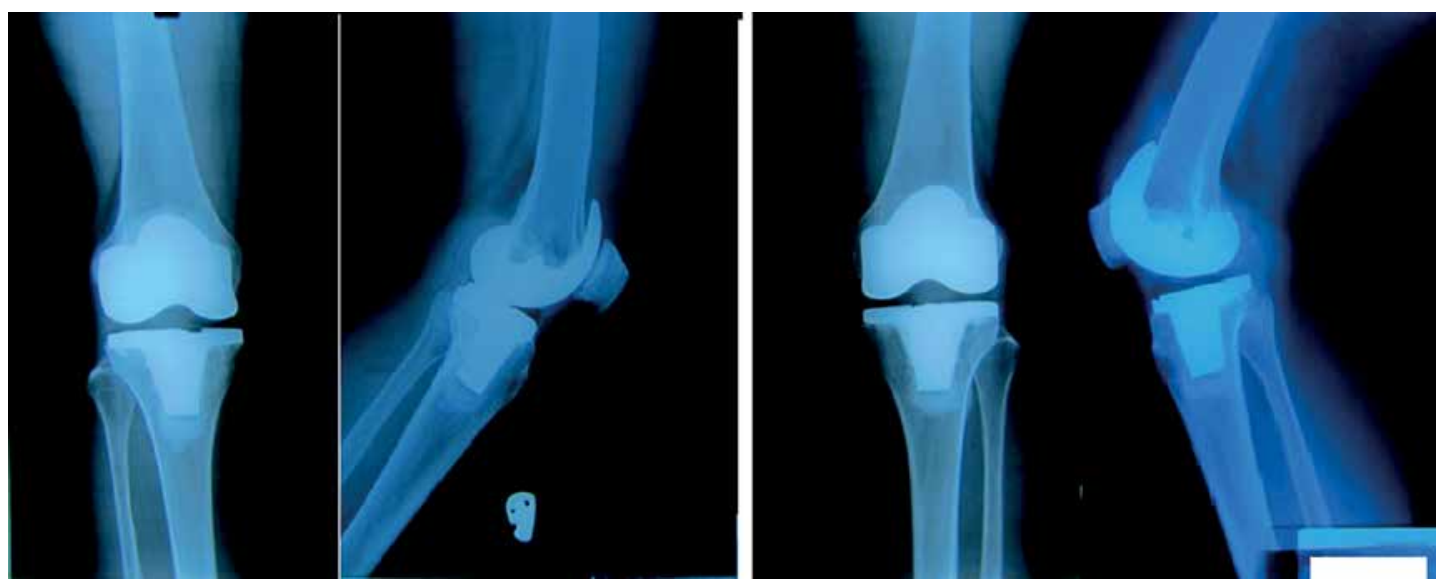

Figure 1. Five-year postoperative radiograph of a bilateral total knee replacement surgery 
the service life of fixed parts and thus reduce the likelihood of revision endoprosthetics within the short-term and midterm framework.

According to the WHO, patient's QoL is the proper criterion to characterize the effectiveness of rehabilitation of patients suffering from knee arthrosis. This criterion can be assessed using any scoring system from the range of internationally recognised scoring systems.

The purpose of this research is to make a retrospective review of the quality of life of patients with knee arthrosis, who underwent total knee arthroplasty (TKA) no less than 5 years ago, to evaluate, based on the Knee Society Scoring System, the efficacy of a modified measured resection technique, and to investigate factors that affect the outcomes.

\section{Material and methods}

The research sample consisted of 44 patients (45 knee joints): 32 women and 12 men, who had severe osteoarthrosis, Kellgren-Lawrence grade III and grade IV. Kellgren-Lawrence grade III is characterised by multiple osteophytes, definite joint space narrowing, sclerosis, and possible bony deformity. Kellgren-Lawrence grade IV is characterised by large osteophytes, marked joint space narrowing, severe sclerosis, and definitely bony deformity.

Inclusion criteria: patients underwent posteriorstabilised, cemented, and fixed bearing total knee arthroplasty at the Saint Paul Hospital, Hanoi (one of the patients had both knees resurfaced); surgery was performed by same team of surgeons; all patients underwent modified measured resection; the knee replacement implant fixed with cement was a Press Fit Condylar (PFC) Total Knee System from DePuy Synthes; the presence of a complete record and follow-up for at least 2 years; patients gave consent to participate in the study; and patients lived a short distance from the hospital.

The preoperative diagnosis implied the X-ray examination using a standard $X$-ray machine and a negatoscope. The knee replacement surgery was performed using special instruments from the same manufacturer, a medical drill with attachments, two types of saws, oscillating and reciprocating, with blades attached, and the PMMA bone cement.

To prevent the occurrence of surgical site infections in the post-operative period, drug-induced and non-drug prevention measures were undertaken. Among these, drugs were used to prevent bone mineral density reduction and to treat osteoporosis. Specific and non-specific prevention methods were applied to prevent venous thromboembolic complications. Within the framework of postoperative rehabilitation, 15 patients had to accomplish the full rehabilitation protocol, while the rest of 29 patients (30 knee joints) had to accomplish only part of it, depending on the condition. The postoperative complications were recorded directly after detection. The post-operative results were evaluated with the Knee Society Scoring System [22, 23]. This system has a 100-point scale for knee rating and functional assessment. The score includes three main parameters (pain, stability, and range of motion) and other parameters (contraction of flexion, loss of extension and alignment) considered as deductions. Thus, the maximum score of 100 points (pain: 50 points, stability: 25 points, range of motion: 25 points) is reached when there is no pain, with good alignment of the knee in extension, and at least $125^{\circ}$ range of motion, without any anteroposterior or mediolateral instability. The function score evaluates the walking distance with deductions for walking aids, totalling 50 points, and the act of climbing and descending stairs, also totalling 50 points. The maximum score of 100 points is attributed to an individual capable of walking unlimited distances without walking aids, and of climbing and descending stairs normally. The walking ability is expressed in blocks (approximately $100 \mathrm{~m}$ ). Stair climbing is considered normal if the patient can ascend and descend stairs without holding a railing.

The follow-up period ranged from 5.2 to 7.8 years, 73 months on average. The literature on similar operations does not provide a universal standard for a follow-up period. Follow-up periods of 3 to 14 years [24-28] and 5 to 6 years are often used [29-31]. This study used a period from five years because it is enough time for adaptation to a new knee system and lifestyle, which provokes an objective assessment of outcomes. A longer period of follow-up was not considered because the analysis of long-term QoL in elderly patients could become dependent upon factors unrelated to TKA. At the time of this research, the average age of the patients was $68.9 \pm 9.4$ years (range: $41-88$ years), and $62.7 \pm 8.4$ years at the time of surgery (range: $36-81$ years). Factors that affected the quality of life of the patients were assessed with regard to the body mass index (BMI) score, associated diseases (if any detected), and rehabilitation compliance. The general characteristics of patients at the time of retrospective study are presented in Table I.

\section{Results and discussion}

Even though new technologies are being introduced, the rate of complications from knee arthroplasty, as well as poor outcomes, is still high, amounting to $3.3-13.2 \%$. The incidence of surgi- 
Table I. General characteristics of 44 patients who underwent total knee arthroplasty: data collected at the time of retrospective study ( 5.2 to 7.8 years after surgery)

\begin{tabular}{|c|c|c|}
\hline Characteristics & $N$ & $\%$ \\
\hline \multicolumn{3}{|l|}{ Gender: } \\
\hline Female & 32 & 72.7 \\
\hline Male & 12 & 27.3 \\
\hline \multicolumn{3}{|l|}{ Age: } \\
\hline $40-49$ & 2 & 4.5 \\
\hline $50-59$ & 3 & 6.8 \\
\hline $60-69$ & 17 & 38.6 \\
\hline $70-79$ & 15 & 34.1 \\
\hline$\geq 80$ & 7 & 15.9 \\
\hline \multicolumn{3}{|l|}{ BMI score: } \\
\hline Normal weight (18.5-22.9) & 15 & 34.1 \\
\hline At risk of overweight (23-24.9) & 12 & 27.3 \\
\hline Overweight BMI > 25.0 & 17 & 38.6 \\
\hline \multicolumn{3}{|l|}{ Involved knee: } \\
\hline Left & 20 & 45.5 \\
\hline Right & 23 & 52.2 \\
\hline Both & 1 & 2.3 \\
\hline \multicolumn{3}{|l|}{ Associated disease: } \\
\hline Cardiologic & 13 & 29.5 \\
\hline Diabetes & 10 & 22.7 \\
\hline Rheumatoid arthritis & 1 & 2.3 \\
\hline None & 20 & 45.5 \\
\hline
\end{tabular}

$B M I$ - body mass index.

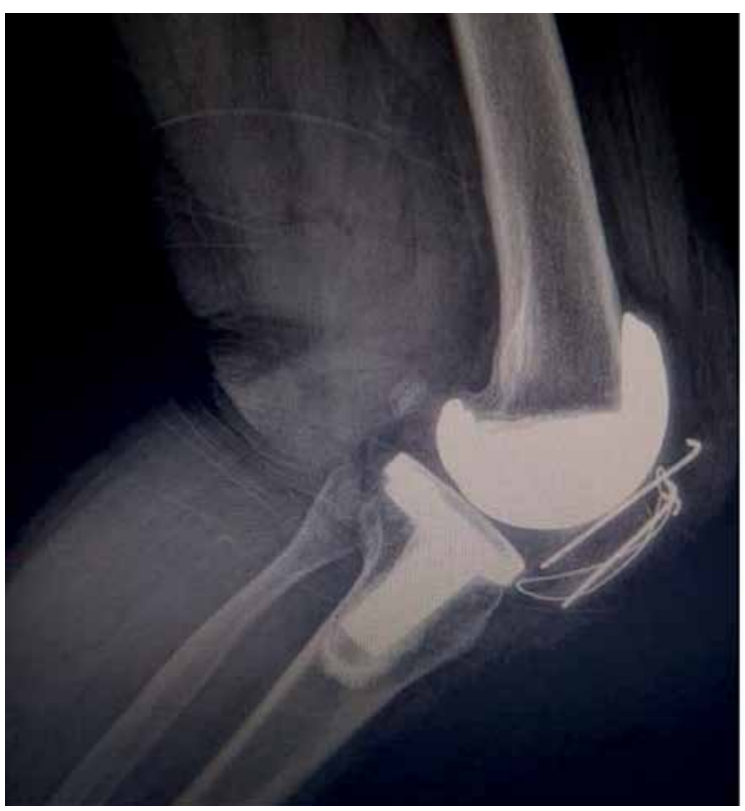

cal site infections in primary knee replacement is between 0.5 and $3.5 \%[32,33]$. The frequency of complications, such as femoropatellar pain, aseptic instability, and contracture, may reach 3 to $12 \%$ [34]. The frequency of deep vein thrombosis after knee arthroplasty varies from 41 to $88 \%$; proximal cases are detected in $5-22 \%$ of patients; with no thromboprophylaxis, pulmonary embolism occurs in $1.5-10 \%$ of patients, and is fatal in $0.1-1.7 \%$ of cases [35, 36]. The literature reports some cases of stress fractures of the hip [37-39]. In earlier studies there is evidence of a significant number of post-operative complications in patients undergoing TKA. Thus, Scott et al. reported 13.1\% of cases with complications after TKA, including deep infections, delayed healing (three knees), death, urinary tract infection (two each), hepatitis (one knee), and patella fracture (six knees) [40]. Callahan et al. reported $18 \%$ of patients with post-operative complications after TKA, including: superficial infections - 3.9\% (range: 0-14.8\%); deep infections $-1.7 \%$ (range: $0-11.4 \%$ ); pulmonary embolism - 2\% (range: 0-9.7\%); deep vein thrombosis - 6.5\% (range: 0-56.6\%); and peripheral nerve injury $-2.1 \%$ (range: $0-18.8 \%$ ) [41]. Diduch et al. reported: late infection (two out of 103 knee joints, or $2 \%$ ); polyethylene thinning and instability requiring change of the tibial component (1 case each, or 1\% each); and tibial component dislocation (3 cases, or 3\%) [24]. Katchky found seven major complications (7\%) in patients with SAIPH TKA: one infection, two deep vein thromboses, one cerebrovascular event, and 2 patients with stiffness requiring manipulation under anaesthesia [31]. Wilson noted a significantly higher number of venous thromboembolic events and major cardiac events after TKA following unicom-

Figure 2. The two periprosthesis fractures were treated by osteosynthesis

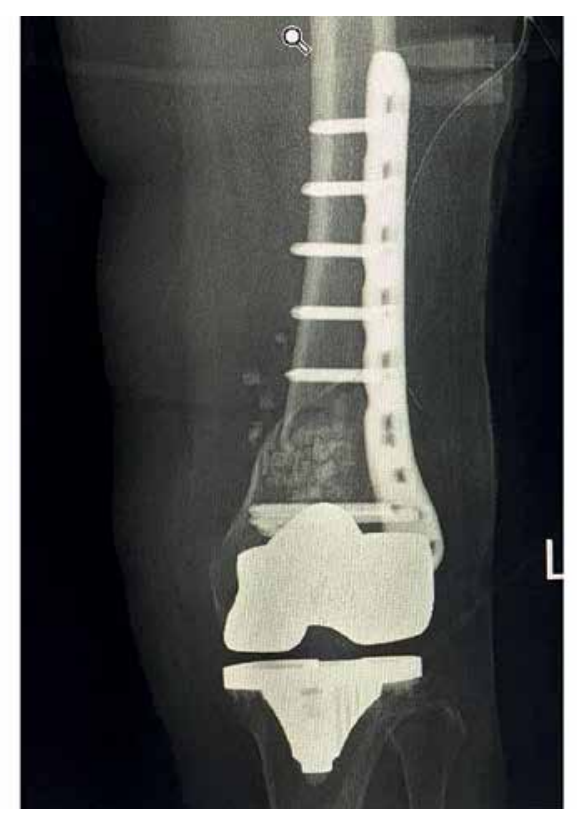


partmental knee arthroplasty (UKA). Moreover, early reoperation for any reason was also higher after TKA than after UKA, but revision rates at 5 years remained higher for UKA [42].

In this research, post-operative complications occurred in seven out of 45 knee joints, or in $15.2 \%$. Among these, there were 2 cases of infection, 2 cases of periprosthesis fracture (Figure 2), and 2 cases of aseptic instability, each pair accounting for $4.3 \%$, and 1 case of femoropatellar pain $(2.3 \%)$. The remaining 38 knee joints $(84.8 \%)$ were free of complications. To prevent excessive blood loss and thrombosis, surgeons used a tranexamic acid, intravenous injection of which is as effective as intra-articular injection [43]. None of deep vein thrombosis, pulmonary embolism, neurovascular or peroneal nerve injury cases were recorded. Thus, pharmacological and non-pharmacological prevention of surgical site infections minimised their frequency rate. The comprehensive diagnosis together with druginduced prevention of bone mineral density reduction and osteoporosis treatment enabled a reduction of early revision risk in patients undergoing knee arthroplasty. Adequate courses of specific and nonspecific preventive treatment performed at appropriate doses to prevent thromboembolic complications from occurring postoperatively, as well as the use of modern anticoagulants in tablet form, prevents the thrombosis from developing in patients. In general, the rate of post-operative complications in this research matches that indicated in other studies.

The postoperative outcomes assessed by the knee score are presented in Table II. The final score of 85 to 100 points was considered excellent, 70 to 84 good, 60 to 69 fair, and less than 60 poor. There were 36 excellent outcomes, or $80.0 \%$; six good, or $13.3 \%$; two fair, or $4.4 \%$; and one poor outcome, or $2.2 \%$. Thus, 42 knee joints, or $93.3 \%$, had good to excellent outcomes postoperatively. The mean knee score was $90.3 \pm 10.8$ points (min. 45; max. 100). In the "Range of motion" item (maximum flexion ability), 6 cases were marked with insignificantly reduced range of movement (13.3\%), 34 with moderate reduction (75.6\%), and five with significant reduction (11.1\%).

According to the literature, excellent and good outcomes account for $90-98 \%$ of cases in the follow-up period of 3 to 14 years [24-31], depending on the type of prosthesis and on the surgical technique. Thus, the results of this retrospective research are similar to those published by other authors, indicating the effectiveness of modified measured resection in cemented total knee arthroplasty performed with the PFC Total Knee System (Table II).

The patient-reported portion (function score) of the Knee Society Score is presented in Table III.
There were 28 excellent outcomes, or $62.2 \%$; seven good, or $15.6 \%$; two fair, or $4.4 \%$; and eight poor outcomes, or $17.8 \%$. Thus, 35 knee joints, or $77.8 \%$, had good to excellent outcomes postoperatively. The average function score was 78.2 \pm 24.1 points (min. 10; max. 100). As in our case, data in the literature indicate that function scores are somehow markedly different from the knee scores. Thus, Ahmad Hafiz et al. reported an average of $62.54 \pm 16.68$ points (range: $5-90$ points) [44]. Duffy et al. reported a postoperative average of 60 points (range: $0-100$ points), with good to excellent scores accounting for $78.3 \%$, and with poor scores accounting for $29.7 \%$ of patients [45]. Dhillon et al. reported a fifty-fifty result [46]. They noted that poor outcomes were mainly in patients

Table II. Post-operative knee score $(n=45)$

\begin{tabular}{|c|c|c|}
\hline Parameter & $N$ & $\%$ \\
\hline \multicolumn{3}{|l|}{ Pain syndrome: } \\
\hline None & 35 & 77.8 \\
\hline Mild, occasional & 2 & 4.44 \\
\hline Mild, stairs only & 2 & 4.44 \\
\hline Mild, walking & 4 & 8.88 \\
\hline Moderate, occasional & 2 & 4.44 \\
\hline Moderate, continual & 0 & 0 \\
\hline \multicolumn{3}{|l|}{ Alignment: } \\
\hline $5-10^{\circ}$ & 44 & 97.8 \\
\hline $0-4^{\circ}$ & 1 & 2.2 \\
\hline $11-15^{\circ}$ & 0 & 0 \\
\hline \multicolumn{3}{|l|}{ Knee stability: } \\
\hline Mediolateral $<5^{\circ}$ & 42 & \\
\hline Mediolateral $5-15^{\circ}$ & 2 & 4.3 \\
\hline Mediolateral > $15^{\circ}$ & 1 & 2.2 \\
\hline Anteroposterior > $5 \mathrm{~mm}$ & 0 & 0 \\
\hline \multicolumn{3}{|c|}{ Range of motion (maximum flexion ability): } \\
\hline $0-79^{\circ}$ & 1 & 2.2 \\
\hline $80-89^{\circ}$ & 5 & 11.1 \\
\hline $90-99^{\circ}$ & 14 & 31.1 \\
\hline $100-109^{\circ}$ & 20 & 44.4 \\
\hline $110-119^{\circ}$ & 1 & 2.2 \\
\hline $120-129^{\circ}$ & 4 & 8.9 \\
\hline \multicolumn{3}{|c|}{ Extension deficit (extension lag): } \\
\hline $5-10^{\circ}$ & 2 & 4.4 \\
\hline None & 43 & 95.6 \\
\hline
\end{tabular}


Table III. Post-operative knee function $(n=44)$

\begin{tabular}{|c|c|c|}
\hline Parameters & $N$ & $\%$ \\
\hline \multicolumn{3}{|c|}{ Walking ability (distance walked): } \\
\hline Unlimited & 26 & 59.1 \\
\hline$>10$ blocks & 9 & 20.5 \\
\hline $5-10$ blocks & 5 & 11.4 \\
\hline$<5$ blocks & 2 & 4.5 \\
\hline Housebound & 1 & 2.3 \\
\hline Unable & 1 & 2.3 \\
\hline \multicolumn{3}{|l|}{ Ability to climb stairs: } \\
\hline Normal, up and down & 15 & 34.1 \\
\hline $\begin{array}{l}\text { Normal up; down with } \\
\text { the support of the rail }\end{array}$ & 17 & 38.6 \\
\hline $\begin{array}{l}\text { Up and down with the } \\
\text { support of the rail }\end{array}$ & 4 & 9.1 \\
\hline $\begin{array}{l}\text { Up with the support } \\
\text { of the rail, unable to } \\
\text { climb down }\end{array}$ & 6 & 13.6 \\
\hline Unable & 2 & 4.5 \\
\hline \multicolumn{3}{|l|}{ Ability to rise from a chair: } \\
\hline Normal & 14 & 31.8 \\
\hline With support of a rail & 18 & 40.9 \\
\hline $\begin{array}{l}\text { Difficult, with support } \\
\text { from others }\end{array}$ & 11 & 25.0 \\
\hline Unable & 1 & 2.3 \\
\hline \multicolumn{3}{|l|}{ Walking aids: } \\
\hline None & 34 & 77.3 \\
\hline Cane & 6 & 13.6 \\
\hline Two canes & 1 & 2.3 \\
\hline Crutches or walker & 2 & 4.5 \\
\hline Unable to walk & 1 & 2.3 \\
\hline
\end{tabular}

with rheumatoid arthritis. Even though the knee score improved, the function score remained poor due to multiple joint diseases. For patients with osteoarthritis, outcomes improved, but the function score remained low due to their lifestyles. Some of the patients led sedentary lifestyles, and they refused to walk long distances or go up the stairs. Some preferred to use a cane because it gave them greater confidence. These factors reduced their function score. More than half (53.1\%) of the patients with rheumatoid arthritis had poor outcomes, and only $21.9 \%$ of patients with osteoarthritis had better outcomes. Thus, the function score is subjective a score that depends on the patient's lifestyle. The patient can evaluate his/her functionality when walking long distances and going up and down the stairs not only by referring to their knee joints, but also via other factors. This is why function scores are often lower than objective knee scores. The functional status assessment is subjective and affects patient satisfaction after TKA. Thus, Katchky indicate that despite generally good outcomes after TKA, between 15\% and 20\% of patients remain dissatisfied [31]. This number decreases over time as patients adapt to their knee systems [47, 48] (Table III).

The advantage of the Knee Society Scoring System is that neither age nor the general health condition of the patient affects the scoring, but such factors as age, body mass index, rehabilitation compliance, and the presence of other diseases like diabetes may be a factor. Thus, it would be reasonable to analyse their effect on both clinical and functional scores, and specifically on the range of motion (ROM) domain. The results of this analysis are presented in Table IV.

The research sample consisted of 6 patients under 60 years of age and 38 patients (39 knee joints) over 60 years of age. Despite the lack of uniformity in the sample, all patients under the age of 60 years scored the highest on both scales (mean function score: $90.0 \pm 8.9$; mean knee score: $94.5 \pm 1.8)$, while older patients scored lower (mean function score: $76.4 \pm 25.2$; mean knee score: $89.7 \pm 11.5$ ). There were no noticeable differences in the ROM value between the two groups. Patients who followed the full rehabilitation protocol demonstrated significantly better results (mean function score: 91.0 \pm 12.1 ; mean knee score: $94.1 \pm 6.7$; mean ROM: $\left.103.5^{\circ} \pm 10.6^{\circ}\right)$ than those patients, who, for various reasons, took only some rehabilitation measures from the protocol (mean function score: $71.8 \pm 26.1$; mean knee score: $88.4 \pm 12.1$, mean ROM: $95.8^{\circ} \pm 19.7^{\circ}$ ). The body mass index (BMI) is a very important factor influencing both the frequency of post-operative complications and knee function restoration after surgery. Excessive weight increases the time of rehabilitation, while the increased load on the joint significantly reduces the functional performance of the knee joint and the lifespan of the implant [48]. In this research, overweight patients $\left(B M I \geq 25 \mathrm{~kg} / \mathrm{m}^{2}\right)$ showed the worst outcomes (mean function score: $70.0 \pm 27.5$; mean knee score: $84.1 \pm 14.1$; mean ROM: $\left.90.7^{\circ} \pm 24.5^{\circ}\right)$ compared to patients with normal weight (mean function score: 83.2 \pm 20.7 ; mean knee score: $94.1 \pm 5.9$; mean ROM: $103.0^{\circ} \pm 9.1^{\circ}$ ). This necessitates constant weight control. Patients suffering from diabetes scored worse (mean function score: $73.0 \pm 27.9$; mean knee score: $87.0 \pm 10.9)$ than those without this pathology (mean function score: $79.7 \pm 23.1$; 
Table IV. Factors affecting flexion

\begin{tabular}{|c|c|c|c|c|}
\hline Factors & $N$ & $\begin{array}{c}\text { KFS score } \\
(\text { mean } \pm \text { SD) }\end{array}$ & $\begin{array}{c}\text { KS score } \\
(\text { mean } \pm S D)\end{array}$ & $\begin{array}{l}\text { Range of motion } \\
\quad(\text { mean } \pm \text { SD) }\end{array}$ \\
\hline \multicolumn{5}{|l|}{ Age: } \\
\hline$<60$ & 6 & $90.0 \pm 8.9$ & $94.5 \pm 1.8$ & $97.8 \pm 9.1^{\circ}$ \\
\hline$\geq 60$ & 39 & $76.4 \pm 25.2$ & $89.7 \pm 11.5$ & $98.4 \pm 18.5^{\circ}$ \\
\hline \multicolumn{5}{|c|}{ Post-op. rehabilitation: } \\
\hline Inadequate & 30 & $71.8 \pm 26.1$ & $88.4 \pm 12.1$ & $95.8 \pm 19.7^{\circ}$ \\
\hline Full protocol & 15 & $91.0 \pm 12.1$ & $94.1 \pm 6.7$ & $103.5 \pm 10.6^{\circ}$ \\
\hline \multicolumn{5}{|l|}{ BMI $\left[\mathrm{kg} / \mathrm{m}^{2}\right]:$} \\
\hline$<25$ & 28 & $83.2 \pm 20.7$ & $94.1 \pm 5.9$ & $103.0 \pm 9.1^{\circ}$ \\
\hline$\geq 25$ & 17 & $70.0 \pm 27.5$ & $84.1 \pm 14.1$ & $90.7 \pm 24.5^{\circ}$ \\
\hline \multicolumn{5}{|l|}{ Diabetes: } \\
\hline None & 35 & $79.7 \pm 23.1$ & $91.3 \pm 10.7$ & $98.1 \pm 19.8^{\circ}$ \\
\hline Diabetes & 10 & $73.0 \pm 27.9$ & $87.0 \pm 10.9$ & $99.1 \pm 2.2^{\circ}$ \\
\hline
\end{tabular}

$B M I-$ body mass index.

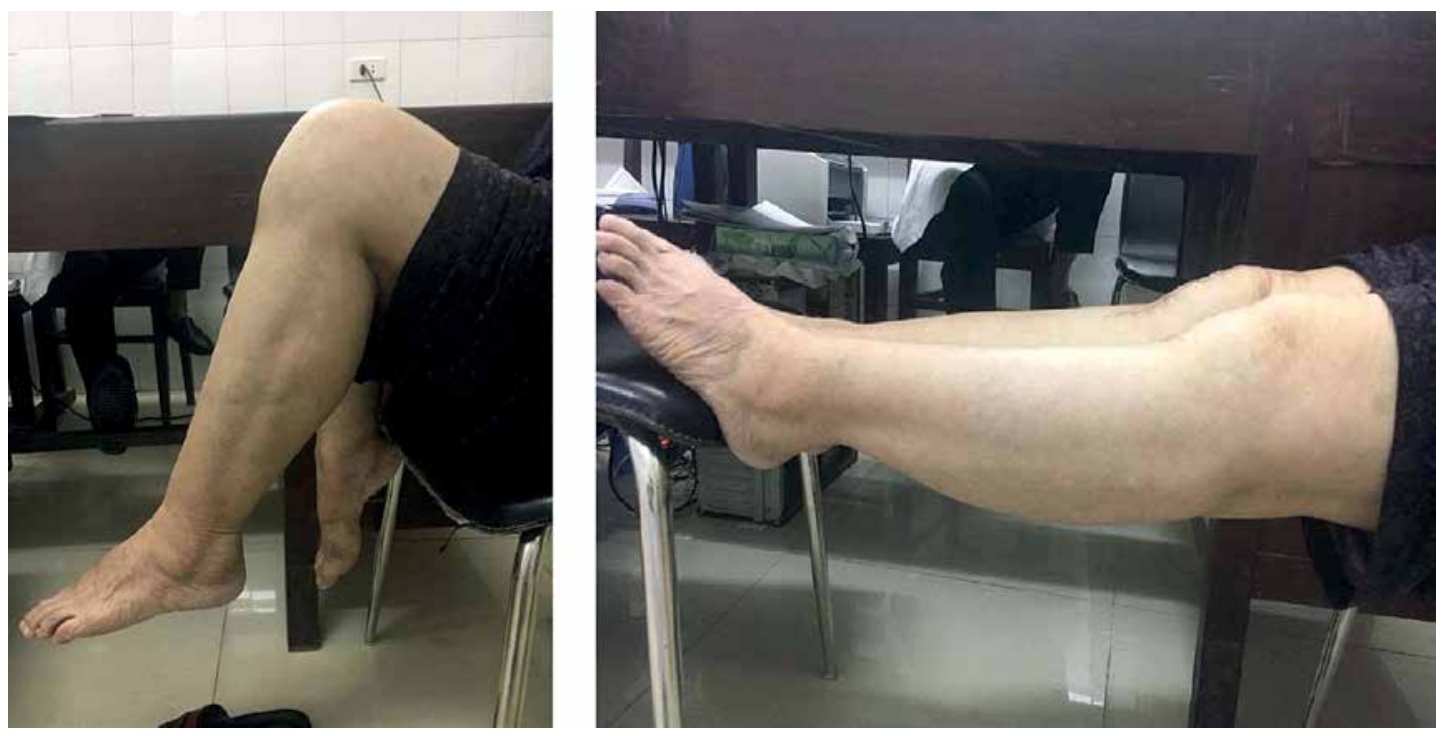

Figure 3. Five-year postoperative range of motion of a patient: maximum flexion was $95^{\circ}$ and full knee extension

mean knee score: $91.3 \pm 10.7$ ), but the worst result was for the combination of diabetes and obesity. As for the ROM, no significant difference was found between patients with and without diabetes. Thus, older age, diabetes, reduced rehabilitation procedures, and overweight negatively affect the outcomes and the knee function; also, the last two factors affect the ROM value (Figure 3 ).

In conclusion, a satisfactory level of post-operative complications was successfully achieved. The modified measured resection followed by the fixation of a PFC Total Knee System enabled the improvement of the patient's health status (93.3\% of good to excellent knee scores postop- eratively) and knee function (77.8\% of good to excellent function scores postoperatively) over 5.2 to 7.8 years, or over 73 months on average. Some factors like older age, the presence of diabetes, the lack of rehabilitation procedures, and overweight have an adverse effect on the outcomes. Thus, patients at risk of developing obesity, or with obesity, should have their weight under constant control. The approach to rehabilitation procedures and, in some cases, to lifestyle improvement should be more responsible as well.

\section{Conflict of interest}

The authors declare no conflict of interest. 
References

1. Cross M, Smith E, Hoy D, et al. The global burden of hip and knee osteoarthritis: estimates from the global burden of disease 2010 study. Ann Rheum Dis 2014; 73: 1323-30.

2. Naghavi M, Lozano R, Michaud C, et al. Years lived with disability (YLDs) for 1160 sequelae of 289 diseases and injuries 1990-2010: a systematic analysis for the Global Burden of Disease Study 2010. Lancet 2012; 380: 2163-96.

3. Arden N, Blanco F, Cooper C, et al. Atlas of Osteoarthritis. Springer, London 2015; 21.

4. Glyn-Jones S, Palmer AJ, Agricola R, et al. Osteoarthritis. Lancet 2015; 386: 376-87.

5. Bijlsma JWJ (ed.). EULAR Compendium on Rheumatic Disease. BMJ Publishing, London 2009; 824.

6. Issa SN, Sharma L. Epidemiology of osteoarthritis: an update. Curr Rheumatol Rep 2006; 8: 7-15.

7. Nelson AE, Renner JB, Schwartz TA, Kraus VB, Helmick CG, Jordan JM. Differences in multijoint radiographic osteoarthritis phenotypes among African Americans and Caucasians: the Johnston County Osteoarthritis project. Arthritis Rheum 2011; 63: 3843-52.

8. Sellam J, Herrero-Beaumont G, Berenbaum F. Osteoarthritis: pathogenesis, clinical aspects and diagnosis. In: Bijlsma JWJ, Burmeister GR, Da JAP, Faarvang KL, Hachulla E, Mariette X (eds.). EULAR Compendium Rheumatic Diseases. BMJ Publishing Group, London 2009; 444-63.

9. Brandt KD, Dieppe P, Radin E. Etiopathogenesis of osteoarthritis. Med Clin North Am 2009; 93: 1-24.

10. Smith RL. Mechanical loading effects on articular cartilage matrix metabolism and osteoarthritis. Osteoarthritis, Inflammation and Degradation: A Continuum. IOS Press 2007; 14-30.

11. Bagirova GG. Selected Lectures in Rheumatology. Meditsina, Moscow 2008; 256.

12. March L, Smith EU, Hoy DG, et al. Burden of disability due to musculoskeletal (MSK) disorders. Best Pract Res Clin Rheumatol 2014; 28: 353-66.

13. Madry H, Luyten FP, Facchini A. Biological aspects of early osteoarthritis. Knee Surg Sports Traumatol Arthrosc 2012; 20: 407-22.

14. Englund M, Roemer FW, Hayashi D, Crema MD, Guermazi A. Meniscus pathology, osteoarthritis and the treatment controversy. Nat Rev Rheumatol 2012; 8: 412-9.

15. Li G, Yin J, Gao J, et al. Subchondral bone in osteoarthritis: insight into risk factors and microstructural changes. Arthritis Res Ther 2013; 15: 223.

16. Malanin DA, Pisarev VB, Novochadov VV. Restoration of cartilage injuries in knee joints. Volgograd 2010; 454

17. Sultan PG, Most E, Schule S, Li G, Rubash HE. Optimizing flexion after total knee arthroplasty: advances in prosthetic design. Clin Orthop 2003; 416: 167-73.

18. Santaguida PL, Hawker GA, Hudak PL, et al. Patient characteristics affecting the prognosis of total hip and knee joint arthroplasty: a systematic review. Can J Surg 2008; 51: 428-36.

19. Carr AJ, Robertsson O, Graves S, et al. Knee replacement. Lancet 2012; 379: 1331-40.

20. Jenkins PJ, Clement ND, Hamilton DF, Gaston P, Patton JT, Howie CR. Predicting the cost-effectiveness of total hip and knee replacement: a health economic analysis. Bone Joint J 2013; 95-B: 115-21.

21. Daigle ME, Weinstein AM, Katz JN, Losina E. The costeffectiveness of total joint arthroplasty: a systematic review of published literature. Best Pract Res Clin Rheumatol 2012; 26: 649-58.
22. Scuderi GR, Bourne RB, Noble PC, Benjamin JB, Lonner JH, Scott WN. The New Knee Society Knee Scoring System. Clin Orthop Relat Res 2012; 470: 3-19.

23. Noble PC, Scuderi GR, Brekke AC, et al. Development of a new Knee Society scoring system. Clin Orthop Relat Res 2012; 470: 20-32.

24. Diduch DR, Insall JN, Scott N, Scuderi GR, Font-Rodriquez D. The total knee replacement in young, active patients. Long term follow-up and functional outcome. J Bone Joint Surg 1997; 79A: 575-82.

25. Hvannberg J, Róbertsson GO, Gestsson J, Ingvarsson T. Knee arthroplasties performed at Akureyri University Hospital in the years 1983-2003. Results with emphasis on revision and complication rates. Laeknabladid 2005; 91: 739-46.

26. Mont MA, Ragland PS. Osteonecrosis of the knee. Surgery of the knee: $4^{\text {th }}$ ed. New York 2006, 460-78.

27. Insall JN, et al. Total knee replastement. Surgery of the knee. $4^{\text {th }}$ ed. New York 2006; 609-33.

28. Powell AJ, Crua E, Chong BC, et al. A randomized prospective study comparing mobile-bearing against fixed-bearing PFC Sigma cruciate-retaining total knee arthroplasties with ten-year minimum follow-up. Bone Joint J 2018; 100-B: 1336-44.

29. Breeman S, Campbell MK, Dakin H, et al. Five-year results of a randomised con-trolled trial comparing mobile and fixed bearings in total knee replacement. Bone Joint J 2013; 95-B: 486-92.

30. Yooum YS, Cho SD, Lee SH, Cho HY. Total knee arthroplasty using a posterior cru-ciate ligament sacrificing medial pivot knee: minimum 5-year follow-up results. Knee Surg Relat Res 2014; 26: 135-40.

31. Katchky AM, Jones CW, Walter WL, Shimmin AJ. Medial ball and socket total knee arthroplastyfive-year clinical results. Bone Joint J 2019; 101-b (1 Suppl A): 59-65.

32. Efimenko NA, Gitsyuk AA, Sereda AP. Antibiotic prophylaxis in trauma and orthopedics. Infektsii v khirurgii 2008; 6: 9-14.

33. Lentino JR. Prosthetic joint infections: bane of orthopedists, challenge for infectious disease specialists. Clin Infect Dis 2003; 36: 1157-61.

34. Rumyantsev $Y$. Radiological diagnosis of complications after hip and knee joints. Radiologiya-praktika 2011; 4: 95-6.

35. Kopenkin SS. Prevention of venous thromboembolic complications in orthopedic surgery: new opportunities. Vestnik travmatologii i ortopedii im. N.N. Priorova 2010; 1: 35-39.

36. Matziolis G, Perka C, Labs K. Acute arterial occlusion after total knee arthroplasty. Arch Orthop Trauma Surg 2004; 124: 134-6.

37. Hardy DCR, Delince PE, Yasik E, Lafontaine MA. Stress fracture of the hip. An unusual complication of total knee arthroplasty. Clin Orthop 1992; 281: 140-4.

38. Rawes ML, Patsalis T, Gregg PJ. Subcapital stress fractures of the hip complicating total knee replacement. Injury 1995; 26: 421-3.

39. Hendel D, Beloosesky Y, Weisbort M. Fracture of the hip after knee arthroplasty - an unusual case with pain in the knee. Acta Orthop Scand 2001; 72: 194-5.

40. Scott WN, Rubinstein M, Scuderi G. Results after knee replacement with a osterior cruciate substituting prosthesis. J Bone Joint Surg 1988; 70A: 1163-73.

41. Callahan CM, Drake BG, Heck DA, Ditlus RS. Patient outcomes following tricompartmental total knee replacement. A meta-analysis. J Am Med Assoc 1994; 217 : 1349-57.

42. Wilson HA, Middleton R, Abram SGF, et al. Patient relevant outcomes of unicompartmental versus total knee 
replacement: systematic review and meta-analysis. BMJ 2019; 365: 11032.

43. Łęgosz P, Sarzyńska S, Pulik $Ł$, et al. Heterotopic ossification and clinical results after total hip arthroplasty using the anterior minimally invasive and anterolateral approaches. Arch Med Sci 2020; 16: 613-20.

44. Ahmad Hafiz Z, Masbah O, Ruslan G. Total knee replacement: 12 years retrospective review and experience. Malays Orthop J 2011; 5: 34-9.

45. Duffy GP, Trousdale RT, Stuart MJ. Total knee arthroplasty in patients 55 years old or younger. 10- to 17-year results. Clin Orthop Relat Res 1998; 356: $22-7$.

46. Dhillon K, Jamal, Bhupinderjeet S. Early results of total knee replacement. A clinical and radiological evaluation. Med J Malaysia 1993; 48: 427-35.

47. Clement ND, Bardgett M, Weir D, et al. Three groups of dissatisfied patients exist after total knee arthroplasty: early, persistent, and late. Bone Joint J 2018; 100-B: 161-9.

48. Sobti AS, Sudhakar JE. High body mass index and its effect on total knee replacement. J Arthritis 2017; 6: 244-5. 